\title{
A global method for calculating plant CSR ecological strategies applied across biomes world-wide
}

Simon Pierce ${ }^{\star, 1}$, Daniel Negreiros ${ }^{2}$, Bruno E. L. Cerabolini ${ }^{3}$, Jens Kattge ${ }^{4}$, Sandra Díaz ${ }^{5}$, Michael Kleyer ${ }^{6}$, Bill Shipley ${ }^{7}$, Stuart Joseph Wright $^{8}$, Nadejda A. Soudzilovskaia ${ }^{9}$, Vladimir G. Onipchenko ${ }^{10}$, Peter M. van Bodegom ${ }^{9}$, Cedric Frenette-Dussault ${ }^{7}$, Evan Weiher ${ }^{11}$, Bruno X. Pinho ${ }^{12}$, Johannes H. C. Cornelissen ${ }^{13}$, John Philip Grime ${ }^{14}$, Ken Thompson ${ }^{14}$, Roderick Hunt $^{15}$, Peter J. Wilson ${ }^{14}$, Gabriella Buffa ${ }^{16}$, Oliver C. Nyakunga ${ }^{16,17}$, Peter B. Reich ${ }^{18,19}$, Marco Caccianiga ${ }^{20}$, Federico Mangili ${ }^{20}$, Roberta M. Ceriani ${ }^{21}$, Alessandra Luzzaro', Guido Brusa $^{3}$, Andrew Siefert ${ }^{22}$, Newton P. U. Barbosa ${ }^{2}$, Francis Stuart Chapin III $^{23}$, William K. Cornwell ${ }^{24}$, Jingyun Fang ${ }^{25}$, Geraldo Wilson Fernandes ${ }^{2,26}$, Eric Garnier ${ }^{27}$, Soizig Le Stradic $^{28}$, Josep Peñuelas ${ }^{29,30}$, Felipe P. L. Melo ${ }^{12}$, Antonio Slaviero ${ }^{16}$, Marcelo Tabarelli ${ }^{12}$ and Duccio Tampucci ${ }^{20}$

\begin{abstract}
${ }^{1}$ Department of Agricultural and Environmental Sciences (DiSAA), University of Milan, Via G. Celoria 2, I-20133 Milan, Italy; ${ }^{2}$ Ecologia Evolutiva e Biodiversidade/DBG, ICB/Universidade Federal de Minas Gerais, CP 486, 30161-970 Belo Horizonte, MG, Brazil; ${ }^{3}$ Department of Theoretical and Applied Sciences, University of Insubria, Via J.H. Dunant 3 , I-21100 Varese, Italy; ${ }^{4}$ Max Planck Institute for Biogeochemistry, P.O. Box 100164, 07701 Jena, Germany; ${ }^{5}$ Instituto Multidisciplinario de Biología Vegetal (CONICET-UNC) and FCEFyN, Universidad Nacional de Córdoba, Av. Vélez Sarsfield 299, $2^{\circ}$ piso. 5000, Córdoba, Argentina; ${ }^{6}$ Department of Biology, Earth and Environmental Sciences, University of Oldenburg, 26111 Oldenburg, Germany; ${ }^{7}$ Département de Biologie, Université de Sherbrooke, Sherbrooke, Quebec J1K 2R1, Canada; ${ }^{8}$ Smithsonian Tropical Research Institute, Apartado, Balboa 0843-03092, Panama; ${ }^{9}$ Institute of Environmental Sciences CML, Leiden University, Einsteinweg 2, 2333 CC Leiden, The Netherlands; ${ }^{10}$ Department of Geobotany, Faculty of Biology, Moscow State University, RU-119991 Moscow, Russia; ${ }^{11}$ Department of Biology, University of Wisconsin-Eau Claire, Eau Claire, Wisconsin 54702-4004, USA; ${ }^{12}$ Departamento de Botânica, Universidade Federal de Pernambuco, Cidade Universitária, Recife 50670-901 PE, Brazil; ${ }^{13}$ SubDepartment of Systems Ecology, Vrije Universiteit, de Boelelaan 1085, 1081 HV Amsterdam, The Netherlands; ${ }^{14}$ Department of Animal and Plant Sciences, University of Sheffield, Alfred Denny Building, Western Bank, Sheffield S10 2TN, UK; ${ }^{15}$ Innovation Centre, College of Life and Environmental Sciences, University of Exeter, Rennes Drive, Exeter EX4 4RN, UK; ${ }^{16}$ Department of Environmental Sciences, Informatics and Statistics, University Ca'Foscari of Venice, Campo Celestia 2737b - Castello, I-30122 Venice, Italy; ${ }^{17}$ College of African Wildlife Management, Mweka (CAWM), P.O. Box 3031, Moshi, Tanzania; ${ }^{18}$ Department of Forest Resources, University of Minnesota, 530 Cleveland Ave. N., St. Paul, Minnesota 55108, USA; ${ }^{19}$ Hawkesbury Institute for the Environment, University of Western Sydney, Penrith, New South Wales 2751, Australia; ${ }^{20}$ Department of Biosciences, University of Milan, Via G. Celoria 26, I-20133 Milano, Italy; ${ }^{21}$ The Native Flora Centre (Centro Flora Autoctona; CFA), c/o Consorzio Parco Monte Barro, via Bertarelli 11, I-23851, Galbiate, LC, Italy; ${ }^{22}$ Department of Evolution and Ecology, University of California, One Shields Avenue, Davis, California 95616, USA; ${ }^{23}$ Department of Biology and Wildlife, Institute of Arctic Biology, University of Alaska Fairbanks, Fairbanks, Alaska 99775-7000, USA; ${ }^{24}$ Evolution \& Ecology Research Centre, School of Biological, Earth and Environmental Sciences, University of New South Wales, Sydney, New South Wales 2052, Australia; ${ }^{25}$ Institute of Botany, The Chinese Academy of Sciences, Xiangshan, Beijing 100093, China; ${ }^{26}$ Department of Biology, Stanford University, Stanford, California 94035, USA, ${ }^{27}$ CNRS, Centre d'Écologie Fonctionnelle et Évolutive (CEFE) (UMR 5175), 1919 Route de Mende, 34293 Montpellier Cedex 5, France, ${ }^{28}$ Gembloux Agro-Bio Tech, Biodiversity and Landscape Unit, University of Liege, Gembloux 5030, Belgium; ${ }^{29}$ Global Ecology Unit CREAF-CEAB-CSIC-UAB, CSIC, Cerdanyola del Vallès, 08193 Barcelona, Catalonia, Spain; and ${ }^{30}$ CREAF, Cerdanyola del Vallès, 08193 Barcelona, Catalonia, Spain
\end{abstract}

*Correspondence author. E-mail: simon.pierce@unimi.it

Correction added after online publication on 8 November 2016: author name Geraldo Wilson Fernandez corrected to Geraldo Wilson Fernandes. 


\section{Summary}

1. Competitor, stress-tolerator, ruderal (CSR) theory is a prominent plant functional strategy scheme previously applied to local floras. Globally, the wide geographic and phylogenetic coverage of available values of leaf area (LA), leaf dry matter content (LDMC) and specific leaf area (SLA) (representing, respectively, interspecific variation in plant size and conservative $v s$. acquisitive resource economics) promises the general application of CSR strategies across biomes, including the tropical forests hosting a large proportion of Earth's diversity.

2. We used trait variation for 3068 tracheophytes (representing 198 families, six continents and 14 biomes) to create a globally calibrated CSR strategy calculator tool and investigate strategy-environment relationships across biomes world-wide.

3. Due to disparity in trait availability globally, co-inertia analysis was used to check correspondence between a 'wide geographic coverage, few traits' data set and a 'restricted coverage, many traits' subset of 371 species for which 14 whole-plant, flowering, seed and leaf traits (including leaf nitrogen content) were available. CSR strategy/environment relationships within biomes were investigated using fourth-corner and RLQ analyses to determine strategy/climate specializations.

4. Strong, significant concordance $(\mathrm{RV}=0.597 ; P<0.0001)$ was evident between the 14 trait multivariate space and when only LA, LDMC and SLA were used.

5. Biomes such as tropical moist broadleaf forests exhibited strategy convergence (i.e. clustered around a CS/CSR median; C:S:R $=43: 42: 15 \%$ ), with CS-selection associated with warm, stable situations (lesser temperature seasonality), with greater annual precipitation and potential evapotranspiration. Other biomes were characterized by strategy divergence: for example, deserts varied between xeromorphic perennials such as Larrea divaricata, classified as S-selected (C:S:R = 1:99:0\%) and broadly R-selected annual herbs (e.g. Claytonia perfoliata; $\mathrm{R} / \mathrm{CR}$-selected; C:S:R = 21:0:79\%). Strategy convergence was evident for several growth habits (e.g. trees) but not others (forbs).

6. The CSR strategies of vascular plants can now be compared quantitatively within and between biomes at the global scale. Through known linkages between underlying leaf traits and growth rates, herbivory and decomposition rates, this method and the strategy-environment relationships it elucidates will help to predict which kinds of species may assemble in response to changes in biogeochemical cycles, climate and land use.

Key-words: community assembly, comparative ecology, Grime's CSR triangle, plant economics spectrum, plant functional type, survival strategy, universal adaptive strategy theory

\section{Introduction}

A common framework for the comparison of organism function within and between ecosystems world-wide can potentially be achieved using the continuous variation evident along spectra of functional (adaptive) traits. The main plant trait spectra evident globally represent variation in plant resource economics (a trade-off between traits conferring resource acquisition and internal conservation) and the size of plants and plant organs (Díaz et al. 2016). These two principal functional trait spectra can be used to assign species a position within multivariate space relative to other species and concurrently to allocate discrete ecological strategy classes (Pierce et al. 2013). These classes are more precise than traditional life-form or 'plant functional type' categories characterized by constant attributes (van Bodegom et al. 2012; Soudzilovskaia et al. 2013). Functional trait spectra may also better reflect the acquisition, use and cycling of energy and matter within the ecosystem. For instance, plant resource economics is a particularly important determinant of photosynthetic carbon fixation, biomass production, litter decomposition and thus ecosystem nutrient availabilities (Grime et al. 1997; Wright et al. 2004; Cornwell et al. 2008; Reich 2014). Ecological strategies reflect viable suites of traits that impact fitness and survival and can also provide a conceptual link between ecology and natural selection. Indeed, recent studies underline the evolutionary history of functional traits (Cornelissen \& Cornwell 2014; Cornwell et al. 2014; Flores et al. 2014; Díaz et al. 2016) and the consistent co-occurrence of particular traits and trait values (Reich 2014; Verheijen et al. 2016). It is now clear that plant size and economics are the most prominent aspects of plant functional variation globally (Díaz et al. 2016), although there is currently no consensus on any particular ecological strategy scheme that can potentially explain why certain 
combinations of trait values are consistently observed under similar circumstances.

A prominent strategy scheme is Grime's (1974, 1977, 2001) competitor, stress tolerator, ruderal (CSR) theory (reviewed by Grime \& Pierce 2012), in which the three principal strategies represent viable trait combinations arising under conditions of competition, abiotic limitation to growth or periodic biomass destruction, respectively. Specifically, C-selected 'competitors' are said to survive in relatively stable, productive habitats via investment of resources in continued vegetative growth and rapid attainment of large individual and organ size to aid resource preemption. S-selected 'stress tolerators' protect metabolic performance in variable and resource-poor environments by investing mainly in capacity to retain resources and repair cellular components in dense, persistent tissues. They may be small or gradually accrue large size over a long life span. $\mathrm{R}$-selection, or ruderalism, involves investment of a large proportion of resources not in the individual but in propagules from which the population can regenerate in the face of repeated lethal biomass destruction events, or disturbances. The world-wide leaf economics spectrum, itself a part of the 'fast-slow' plant economics spectrum (Reich 2014), and the leaf size spectrum are major components of CSR strategy variation (Pierce et al. 2012).

A number of CSR analysis methods have been developed (Grime, Hodgson \& Hunt 1988; Hodgson et al. 1999; Pierce et al. 2013) and have been applied as practical tools to characterize, map and compare vegetation function (Bunce et al. 1999; Hunt et al. 2004; Schmidtlein, Feilhauer \& Bruelheide 2012). They have also been used to investigate and interpret a range of community processes, such as resistance and resilience, coexistence, succession and the relationship between species richness and productivity (Lepš, Osbornová-Kosinová \& Rejmánek 1982; Caccianiga et al. 2006; Cerabolini et al. 2016). However, each CSR analysis method has drawbacks, and all have been calibrated using local floras. Application of CSR analysis is therefore typically applied to herbaceous vegetation in Europe (but see Negreiros et al. 2014; de Paula et al. 2015), while the majority of plant diversity is found in tropical forests (Kreft \& Jetz 2007).

Potential for a global system for comparative plant ecology lies in the fact that variation in leaf economics and leaf size is a ubiquitous phenomenon evident not just for temperate herbs but also for trees, lianas and understorey herbs in tropical forests (Santiago \& Wright 2007). Indeed, other widely used traits are not applicable across lifeforms: for example, plant height cannot be measured for aquatic species, whereas leaf traits allow aquatic and terrestrial species to be compared on an equal footing (Pierce et al. 2012). Leaf area (LA), a key determinant of capacity to intercept light, is one of the most widely available indicators of the size spectrum (Díaz et al. 2016). Large values of specific leaf area (SLA) and, alternatively, of leaf dry matter content (LDMC) are highly representative of the opposite extremes of the economics spectrum and are amongst the most widely available traits in the global TRY plant functional trait data base (see list at www.trydb.org/de/TabDetails.php; Kattge et al. 2011). Data for other key traits such as leaf nitrogen content (LNC) have a much more restricted geographic and phylogenetic coverage (Díaz et al. 2016).

Any generally applicable method for calculating CSR strategies must include ubiquitous traits that can represent the extremes of a trade-off between large size and conservative vs. acquisitive economics. Leaf size and economics traits are widely available, applicable to a range of lifeforms and are highly representative of plant functional trade-offs. Specifically, in the European flora species characterized by high LA do not exhibit high SLA or high LDMC, species exhibiting high LDMC all have small, dense leaves and species with high SLA are small and exhibit low LDMC (Cerabolini et al. 2010). These trade-offs at the level of the leaf are associated with whole-plant and reproductive trade-offs (e.g. species with large leaves tend to have large seeds; Pierce et al. 2014a; Díaz et al. 2016), and it is reasonable to expect leaf-level variation to reflect a substantial portion of overall plant variation (Díaz et al. 2016).

The main aim of the current study was to examine the trade-off between LA, LDMC and SLA variation worldwide in order to assign combinations of leaf traits within the triangle of CSR strategies, and to use this to produce a readily applicable practical tool. This builds on the previous CSR classification system of Pierce et al. (2013) but upscaling of the method using a global calibration has a number of advantages. By using the absolute limits of plant functional trait spectra evident in the world flora, rather than local data ranges, the method is essentially altered from one that compares species relative to one another to become a method bounded by the entire range of plant size and economics currently known for vascular plants (i.e. species are compared against absolute limits). This means that ecologists working in biogeographically distinct contexts world-wide will have a common reference frame. As CSR theory predicts that strategies arise consistently in response to particular conditions, lessons learned in one location are potentially transferable to functionally similar vegetation found on different continents.

At local scales, an average CSR strategy for a plant community can be used to provide a 'functional summary' of vegetation and allow comparison of contrasting circumstances (e.g. Caccianiga et al. 2006). A global methodology could similarly provide functional summaries at larger scales and allow investigation of general relationships between plant functioning and broad-scale environmental parameters operating within and between biomes. There is good reason to expect that a plant functional signal should be apparent even at the scale of biomes. For example, as woody species vary between $\mathrm{C}$ - and S-selected, but no ruderal tree species are apparent (at least in Europe; Pierce et al. 2013) biomes dominated by woody species should 
exhibit clustering of species around the CS-selected region of the CSR triangle (whereas herbaceous species in Europe exhibit a much wider range of strategies; Pierce et al. 2013). Furthermore, strategies can be expected to be mediated by climatic factors such as temperature, potential evapotranspiration and water availability, which are principal determinants of plant survival and vegetation distribution. However, the relationship between plant primary strategies and climate has not previously been investigated, despite the potential importance of plant responses to climatic changes in shaping future vegetation. For the present study, a general prediction can be made that biomes characterized by climatic extremes should include species with a greater degree of functional specialization. For example, in the desert biome plants survive using contrasting life histories that can be summarized as essentially 'ephemeral therophyte' or 'long-lived and durable' (Chesson et al. 2004). We can thus predict that the CSR signature of the desert biome will be polarized between extreme R- and S-selected strategies, and that these too are correlated with climatic factors, particularly precipitation seasonality. Montane grasslands and alpine herbaceous vegetation are known to exhibit CSR strategies that range between $\mathrm{R}$ - and S-selection, with C-selection relatively rare (Caccianiga et al. 2006; Pierce et al. 2007a,b), but these studies have investigated specific plant communities and have not enjoyed the opportunity for comparison with the range of strategies evident within the biome as a whole, or indeed with other biomes. Certain biomes, such as tropical moist broadleaf forest, have yet to be interpreted in a plant functional strategy/climate context. Thus, a secondary aim of the present study was to apply the global CSR analysis tool to determine whether it is possible to discern broad patterns of plant functional variability and specialization in response to climatic factors operating in biomes world-wide.

\section{Materials and methods}

\section{TRAIT DATA}

A total of 116979 plant functional trait records, composed of 38835 individual measurements of leaf area $\left(\mathrm{LA} ; \mathrm{mm}^{2}\right), 48468$ measurements of SLA $\left(\mathrm{mm}^{2} \mathrm{mg}^{-1}\right)$ and 29676 of LDMC (\%), measured from plants growing in nature were obtained from the TRY global trait data base (www.try-db.org; Kattge et al. 2011). This included traits from preceding data bases such as the LEDA traitbase (www.leda-traitbase.org; Kleyer et al. 2008). The data set included records from all continents except Antarctica, from 16 countries and several biogeographical regions within many of these countries (species native range and typical biome information is summarized in Appendix Table S1, Supporting Information). A total of 3068 species growing in a wide range of biomes, including tropical woody vegetation of various types, were represented by complete sets of LA, LDMC and SLA data. Of these species, a subset of 371 species was available for which sets of 14 whole-plant, leaf, flowering and seed traits were available, including the additional traits leaf nitrogen concentration (LNC), leaf carbon concentration (LCC), leaf dry weight (LDW), canopy height $(\mathrm{CH})$, lateral spread (LS), flowering start (FS), flowering period (FP), seed mass (SM), seed volume (SVo), total mass of seeds (TMS) and seed variance (SVa) (these data are available from the TRY data base and are also published as an appendix to Pierce et al. 2014a).

The number of replicate values for each trait of each species was typically between 10 and 15 , but varied from a minimum of 3 to a maximum of 349 . Nomenclature is reported in Appendix Table S1 and follows the Missouri Botanical Garden Tropicos system (www.tropicos.org). Additional taxonomic and growth habit information was obtained from the Encyclopedia of Life (www.eol.org) and GBIF (www.gbif.org/species/search).

\section{PRODUCTION OF A GLOBAL CSR ANALYSIS TOOL}

Global calibration of the CSR tool involved an initial multivariate analysis (PCA) of the key leaf traits (as a method of determining the three-way relationship between traits rather than as an analysis of plant adaptation per se), regression of trait values against PCA axes and the use of these regression equations to produce a Microsoft Excel spreadsheet. This spreadsheet aims to allow novel target species to be compared against the multivariate space over which the global data set was ordinated.

First, a centred Pearson PCA was performed using XLSTAT 2012.5.01 software (Addinsoft, New York, NY, USA) and Varimax rotation applied to the first two axes. As a small number of species with disproportionately large leaves are evident in the world flora, with most species exhibiting smaller leaves, trait values were transformed to constrain the most extreme values and to provide distributions as close as possible to normality prior to PCA. In this case, LA data were standardized using the maximum value, followed by square root transformation (Podani 2007). LDMC data were logit transformed (logit transformation is considered a more appropriate method for proportion data with respect to traditional arcsine transformation; Warton \& Hui 2011), and SLA data were log transformed.

Transformed trait values were regressed against values of the PCA axis along which the trait exhibited maximum variance (e.g. $\operatorname{logSLA}$ against PCA1). The regression equation describing the curve of best fit was then incorporated into a Microsoft Excel spreadsheet that used the equation to compare trait values for any given target species against the global spectrum for that trait. This effectively assigned target species three covarying dimensions: a 'LA dimension' based on PCA2, a 'LDMC dimension' based on positive variability along PCA 1 and a 'SLA dimension' based on negative variation along PCA1. As PCA values may be negative or positive, the minimum (i.e. the most negative) values along PCA axes were then determined for each trait and these were used as a constant, added to all values of each trait in order to translate the trait dimensions into an entirely positive space. The next spreadsheet function determined the maximum values, giving the range of values for each trait. In order to produce ternary coordinates (i.e. three coordinates for a triangular graph), a function was then added to the spreadsheet that summed the three dimensions and divided by 100 , allowing determination of the proportional contributions of LA, LDMC and SLA for each species. Thus, the resulting triangular ordination of species represented a 'trade-off triangle' against which target species can be compared.

As no species exhibited zero leaf area or mass, it was not possible for species to be ordinated along the axes themselves nor at the apices of the trade-off triangle. Thus, a spreadsheet function was implemented that essentially expanded, along the three axes, the space occupied by species to fill the entire ternary plot, resulting in full occupation of the triangle and thus positioning of species within the CSR triangle. This was achieved by multiplication of all values by a rescaling constant that allowed the maximum and minimum values to fully occupy the available 
range. The final spreadsheet (Appendix Table S2: 'StrateFy') is available online as Supporting Information and incorporates all functions to easily allow the CSR analysis of novel plant species from leaf traits.

\section{CORRESPONDENCE BETWEEN VARIATION IN 3 AND 14 FUNCTIONAL TRAITS}

To test whether the three key leaf traits (i.e. LA, LDMC and SLA) can provide a reliable multivariate structure for assigning general ecological strategies to plants, we used the subset of species for which 14 vegetative and reproductive trait data were available without any missing data (see Pierce et al. 2014a). To this end, a co-inertia analysis (hereafter, COIA) is a general and flexible method that measures the concordance (i.e. co-structure) between two multivariate data sets that share the same objects (in this case, species; Dray, Chessel \& Thioulouse 2003). This approach was applied to quantify and test the association between two matrices: (i) three traits per 371 species; and (ii) fourteen traits for the same 371 species. The COIA provides a correlation coefficient ('RV') that measures the strength of the association between matrices. This coefficient is bounded between zero (i.e. no association) and one (i.e. maximum association), with significance ( $P$-value) accessed by a Monte Carlo test (with 100000 permutations). To implement the COIA, a PCA was used for both matrices after data transformation to improve normality. Analyses were carried out using $\mathrm{R}$ software ( $\mathrm{R}$ Development Core Team 2013) with the ADE4 package (Dray \& Dufour 2007).

\section{COMPARISON WITH A LOCALLY CALIBRATED METHOD}

In addition to the new globally calibrated method, CSR ternary triplets were also calculated using the local tool of Pierce et al. (2013; calibrated with six traits for the Flora of Italy) and regression of values obtained using both methods was also performed in order to allow comparison between the locally and globally calibrated techniques.

\section{A TEST USING KNOWN VEGETATION CHANGES ALONG SUCCESSION}

In order to test whether the CSR analysis method agreed with expectations of vegetation responses to an environmental gradient, the StrateFy tool was used to calculate CSR strategies for the species characteristic of four phytosociological syntaxa (i.e. plant communities sensu Braun-Blanquet 1925) associated with a sequence of vegetation development encompassing a primary succession and related pasture vegetation. Specifically, in the European Alps, mobile screes represent highly disturbed environments where vegetation is composed of annual therophytes (phytosociological syntaxon Thlasietea rotundifolii Br.-Bl. et al. 1947). With the development of the vegetation and stabilization of scree debris (and where topography and aspect result in long-lying snow cover), snowbed vegetation arises and is characterized by a mixture of nanophanerophytes and hemicryptophytes (Salicetea herbaceae Br.-Bl. et al. 1947; Tomaselli 1997). This can develop further on acid, nutrient poor soils into a climax vegetation dominated by slow-growing graminoids such as the sedge Carex curvula and the grass Festuca halleri (phytosociological alliance Caricion curvulae Br.-Bl. 1925) (Tomaselli \& Rossi 1994). When these unproductive siliceous grasslands experience grazing by large domestic livestock, dominance shifts towards the rhizomatous mat-grass Nardus stricta and the vegetation alliance is characterized by greater floristic richness than that evident for Caricion curvulae (i.e. syntaxon Nardion strictae Br.-Bl. in Br.Bl. \& Jenny 1926; Gennai et al. 2014). Grazing of alpine pastures increases nutrient turnover rates and selective grazing and the patchy concentration of nutrients following defecation are thought to provide contrasting microsites for a range of life histories, fostering species richness, but with dominant grass species nonetheless exhibiting conservative leaf economics and stress tolerance (Pierce et al. 2007a,b). We expected that along this vegetation sequence plant communities would shift from R-selection towards S-selection and ultimately, in the Nardion pasture, to an intermediate, relatively $\mathrm{C}$-selected mean strategy with a greater range of strategies apparent.

\section{GLOBAL FOURTH-CORNER AND RLQ ANALYSES OF CSR STRATEGY/ENVIRONMENT RELATIONSHIPS}

Globally, the combined fourth-corner and RLQ method of Dray et al. (2014) was used to test the relationship between CSR strategies and environmental variation within biomes. Fourteen biomes were defined according to Olson et al. (2001) and are listed as part of Appendix Table S1. Information regarding the biome(s) within the native range of each species was obtained from the comparison of the global distribution of biomes with the georeferenced records of each species (from GBIF) occurring inside its native range. The native range of each species was obtained from sources such as GRIN taxonomy for plants (www.ars-grin.gov/cgi-bin/npgs/html/ tax_search.pl?language $=$ en), eMonocot (http://emonocot.org) and Catalogue of Life (www.catalogueoflife.org/col/search/all). Additionally, we investigated the CSR strategies evident for life-form categories (tree, shrub, liana, graminoid, forb (i.e. herbaceous dicot), herbaceous vine, annual and biennial herb, perennial herb) and for taxonomic families that were represented by a minimum of 30 species in the data set.

The fourth-corner and RLQ approach involved the simultaneous use of three matrices: (i) a 'community' matrix with sample sites in rows and species in columns; (ii) an environmental matrix with sample sites in rows and environmental variables in columns; and (iii) a functional matrix with traits in rows and species in columns. The fourth-corner approach tests the relationship between each species trait and each environmental variable, while the RLQ analysis tests the co-structure between all species traits with all environmental variables (Dray et al. 2014).

The functional matrix was defined by the 3068 species with three traits (i.e. C, S, R percentages). The 14 world biomes (defined by Olson et al. 2001) were treated as sampling sites, and the presence (incidence) of the 3068 species in these biomes was equivalent to a community matrix. To generate the environmental matrix, we assessed average environmental characteristics for each biome using bioclimatic variables (temperature seasonality, annual mean temperature, precipitation seasonality and annual precipitation) for the recent half-century (1950-2001) obtained from the WorldClim project (Hijmans et al. 2005), in addition to global potential evapo-transpiration (Trabucco \& Zomer 2009), at a spatial resolution of $0.0083^{\circ}\left(\sim 1 \mathrm{~km}^{2}\right)$. Temperature and precipitation seasonality was calculated as the standard deviation of monthly values multiplied by 100 and precipitation seasonality as the coefficient of variation of monthly values (Hijmans et al. 2005). In order to obtain unbiased averages for each biome, we created 200000 uniformly random points for the entire globe, covering all terrestrial biomes, using the package gismo for $\mathrm{R}(\mathrm{R}$ Development Core Team 2013). To conduct the RLQ analysis, a correspondence analysis was used for the community matrix, while a PCA was used for the functional and environmental matrices. For the PCA applied to the functional matrix, species were weighted by their overall relative frequency across biomes (i.e. the number of biomes in which each species occurred), whereas for the PCA applied to the environmental matrix, biomes were weighted by the overall frequency of species observed (Dray \& Dufour 2007). Separate fourth-corner and 
RLQ analyses were conducted for each biome, each analysis involving only species occurring in that biome. Significance was obtained through a Monte Carlo test based on the total co-inertia, using the combined null models 2 (permutation of sampling sites) and 4 (permutation of species) with 50000 permutations per test (Dray et al. 2014). Analyses were carried out using $\mathrm{R}$ software (R Development Core Team 2013) with the ade4 package (Dray \& Dufour 2007).

\section{Results}

'WIDE COVERAGE, FEW TRAITS' VS. 'RESTRICTED COVERAGE, MANY TRAITS'

We found a strong and highly significant concordance between the multivariate space produced by three and 14 traits $(\mathrm{RV}=0.597 ; P<0.001 ;$ Fig. 1$)$ : that is, there was a relatively small loss of information when only three leaf traits were used instead of 14 traits, and the multivariate plant functional space described by leaf traits alone was representative of whole-plant functional variation (Fig. 1).

\section{A GLOBAL CSR ANALYSIS METHOD}

The three-way trade-off between LA, LDMC and SLA for the 3068 species of the main global data set, presented in Fig. 2, confirmed that variation in LA was orthogonal to variation in SLA and LDMC in the world flora. Indeed, SLA and LDMC values ranged in opposite directions between two extremes (negative and positive, respectively) of the first axis of variability (PCA1) and thus an axis of leaf economics (Fig. 2a; for eigenvalues see Fig. 2b). The second axis of variability (PCA2) was delimited by leaf area, with large leaves evident only at intermediate leaf economics (Fig. 2a): species with extremely acquisitive or extremely conservative leaves were consistently small (Fig. 2a), confirming that high values of LA, SLA and LDMC were mutually exclusive in the global data set. In other words, dense, tough leaves were not large; soft, acquisitive leaves were not tough and conservative; only leaves with intermediate economics were large.

Transformed leaf area was highly and positively correlated with PCA2 $\left(R^{2}=0.998, P<0.0001\right)$ following the polynomial linear equation detailed in Fig. S1a. Transformed LDMC was strongly and positively correlated with PCA1 $\left(R^{2}=0.794, P<0.0001\right)$ following the equation presented in Fig. S1b. Log SLA was strongly and negatively correlated $\left(R^{2}=0.782, P<0.0001\right)$ with PCA1 following the equation shown in Fig. S1c. These equations allowed comparison of target plant species with the trade-off between these traits and thus determination of the CSR strategy (see Fig. 3 and the practical tool available as Appendix S2; 'StrateFy').

\section{COMPARISON WITH A LOCALLY CALIBRATED METHOD}

When the degree of C-, S- and R-selection calculated by the globally calibrated method were regressed against $\mathrm{C}, \mathrm{S}$
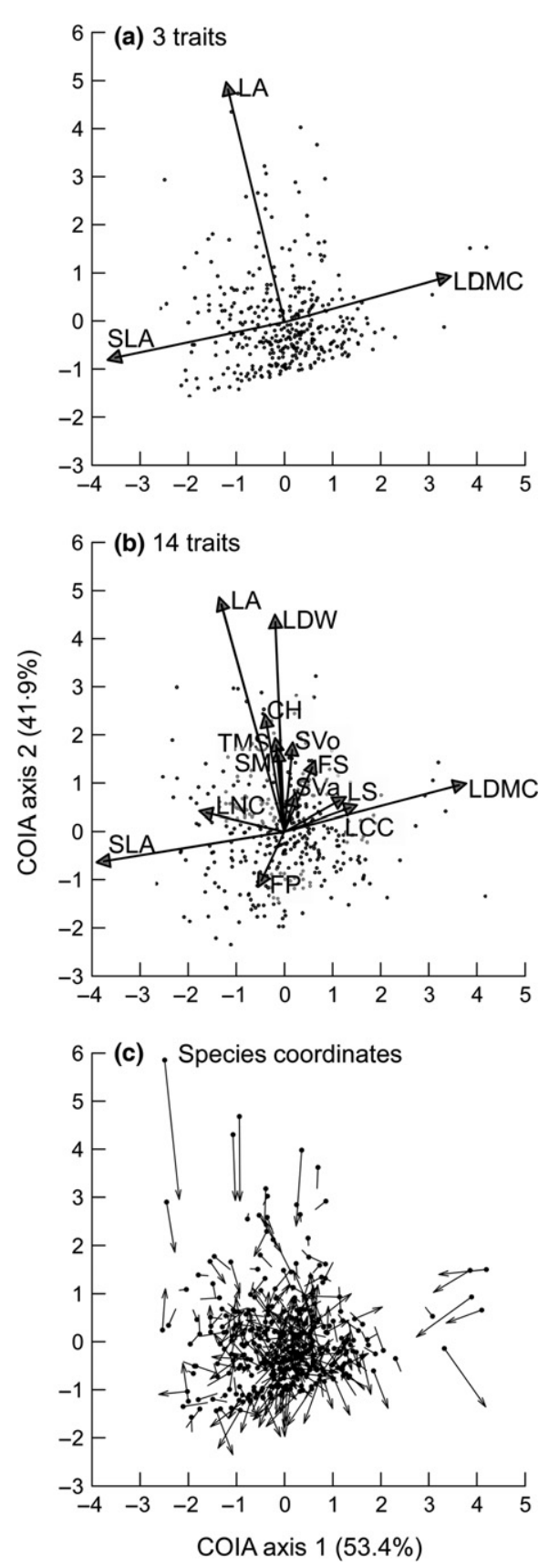

Fig. 1. Projection of two main axes of co-inertia analysis (COIA) for 371 species: variable loadings for data sets including (a) three traits, (b) 14 traits and (c) a joint representation of species scores from the three trait (dots) and 14 trait (arrow tip) data sets. Percentage of variance explained by each axis (eigenvalues) are shown in the axis legend. Traits are $\mathrm{CH}$ : canopy height, FP: flowering period, FS: flowering start, LA: leaf area, LCC: leaf carbon concentration, LDMC: leaf dry matter content, LDW: leaf dry weight, LNC: leaf nitrogen concentration, LS: lateral spread, SLA: specific leaf area, SM: seed mass, SVo: apparent seed volume, SVa: seed variance, TMS: total mass of seeds. Data were log transformed to conform to normality and to constrain extreme values.

and $\mathrm{R}$ values calculated using the method of Pierce et al. (2013), the results were strongly and positively correlated with one another. Specifically, for the degree of C-selection determined by both methods, $R^{2}=0.920, \quad F=9398 \cdot 1$, 


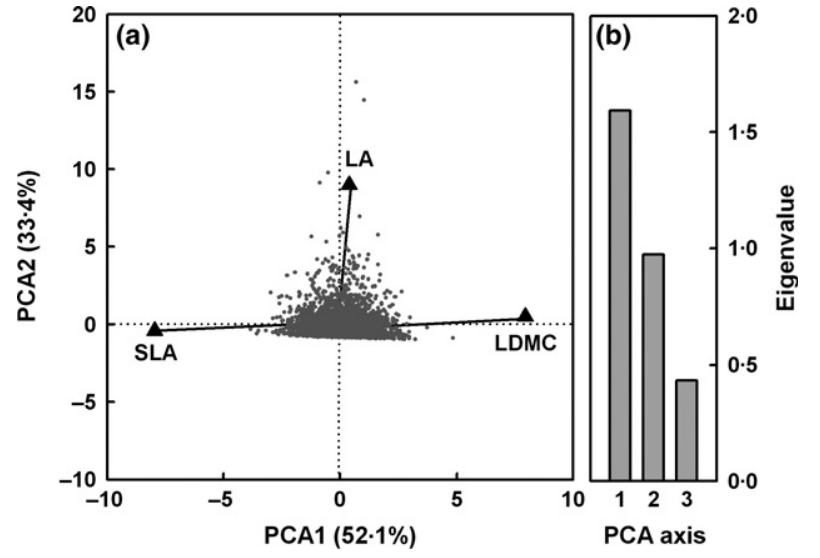

Fig. 2. (a) Biplot showing the relationship between the three traits leaf area (LA), leaf dry matter content (LDMC) and specific leaf area (SLA) for 3068 tracheophyte species from across the world used as a basis for calibrating the CSR classification method (principal components analysis; PCA), and b) eigenvalues for PCA axes. Data were transformed to constrain extreme values (LA was standardized using the maximum value and then square root transformed, SLA was log transformed and LDMC logit transformed).

$P<0.0001, \quad$ for $\quad$ S-selection $R^{2}=0.891, \quad F=24968.3$, $P<0.0001$ and for R-selection $R^{2}=0.866, F=19725.1$, $P<0.0001$ (Fig. S2).

\section{A TEST USING KNOWN VEGETATION CHANGES ALONG SUCCESSION}

The CSR strategies evident for species characteristic of primary succession from scree vegetation to siliceous alpine grassland, terminating with alpine Nardus pasture, are evident in Fig. 4. Pioneer vegetation on screes, as expected, was characterized by mainly R-selected species and exhibited an R-selected mean strategy (C:S:R = 12:0:88\%). Species characteristic of vegetation at an intermediate point along the succession exhibited a mean strategy of SR (4:58:37\%) and species of the climax vegetation exhibited a high degree of stress tolerance (mean strategy $=6: 94: 0 \%$; Fig. 4a). Under pasture, siliceous alpine grassland species exhibited a wider range of strategies encompassing $\mathrm{C} / \mathrm{CR}$-selected species such as Gentiana punctata, S-selected Nardus stricta (3:97:0\%), R/CR-selected species such as Campanula barbata (37:0:63\%) and a mean of CR/ CSR-selection (40:24:36\%; Fig. 4a). The overall trajectory of primary succession in this context is thus characterized by an initial shift from R- to S-selection, with management increasing the range of strategies present and including a higher degree of $\mathrm{C}$-selection relative to the other vegetation types.

\section{CSR STRATEGIES EVIDENT WITHIN BIOMES GLOBALLY}

The CSR strategies evident within biomes were calculated using the globally calibrated CSR analysis tool and are shown in Fig. 5 (details of CSR strategies for each species within every biome are listed in Appendix S1). Tropical and subtropical broadleaf forest (both moist and dry forest biomes) exhibited a broad range of strategies but these were highly clustered around CS/CSR-selected median strategies (for both biomes, median C:S:R $=43: 42: 15 \%$; Fig. 5a,b). Tropical and subtropical coniferous forests also exhibited a median CS/CSR strategy that reflected a slightly greater number of S- and R-selected species at the expense of C-selection (32:46:22\%; Fig. 5c). Tropical and subtropical grasslands, savannas and shrublands were highly represented by CS/CSR-selected species (34:51:15\%; Fig. $5 \mathrm{~g}$ ). In contrast, biomes such as temperate broadleaf and mixed forests (Fig. 5d) and temperate coniferous forests (Fig. 5e) exhibited a SR/CSR-selected median strategy and a wide range of CSR strategies for individual species, filling the CSR triangle relatively uniformly. This denoted the presence and the even distribution of the full gamut of ecological strategies in these biomes. Deserts also exhibited a range of CSR strategies, with a CSR-selected median (Fig. $5 \mathrm{~m}$ ). Other biomes exhibited variation between relatively restricted strategy variation to wide variation (Fig. 5).

Fourth-corner and RLQ analyses for tropical and subtropical broadleaf forest (both moist and dry forest biomes) (Fig. 6a,b) showed that C- and S-selection were highly correlated with environmental variables: positively with annual mean temperature, annual precipitation and global potential evapo-transpiration, but negatively with temperature seasonality $(P<0.05$, and in some cases $P<0.01$ or $P<0.001)$. R-selection exhibited the exact opposite association with environmental variables. In contrast, no significant correlation was found between CSR strategies and environmental variables in temperate broadleaf and coniferous forests (Fig. 6d,e). A wide range of CSR strategies was evident in the desert biome that was significantly correlated with environmental variables: Cand S-selection were positively correlated with annual mean temperature, precipitation seasonality and potential evapo-transpiration, and negatively with temperature seasonality, with R-selection exhibiting contrasting correlations with these factors (Fig. 61).

\section{CSR STRATEGIES WITHIN GROWTH HABIT CATEGORIES AND FAMILIES}

Different growth habit categories exhibited variation in overall and median CSR strategies (Fig. S3). Trees were clustered around a CS median strategy, with no R-selected trees apparent (C:S:R = 43:47:10\%; Fig. S3a) and shrubs centred around an S/CSR strategy (20:61:20\%; Fig. S3b). Lianas were relatively specialized and clustered around CS/CSR-selection (52:35:14\%; Fig. S3c). Graminoids exhibited a strong S-selected component, with variation around an S/CSR median strategy (14:56:29\%; Fig. S3d). Forbs (herbaceous dicots) occupied the entire triangle and exhibited a comparatively generalist R/CSR strategy (30:20:51\%; Fig. S3e). Annual herbs exhibited an R/CSR 


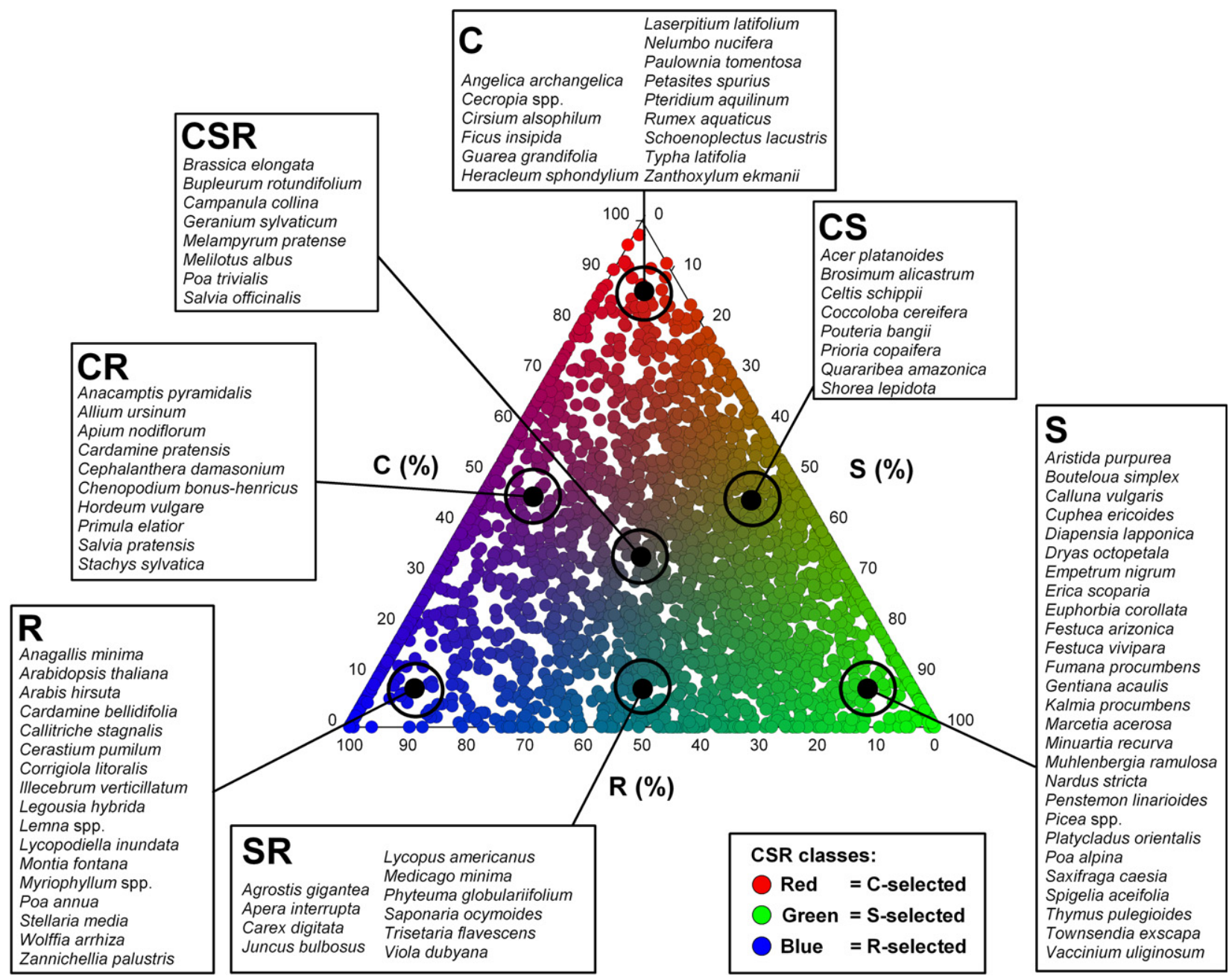

Fig. 3. Relative proportion (\%) of C-, S- and R-selection for 3068 tracheophyte species measured from natural habitats across the world, using the globally calibrated CSR analysis tool 'StrateFy'. Species names represent examples of the seven secondary CSR strategy classes (C, CS, CR, CSR, S, SR and R) suggested by Grime (2001).

median strategy $(25: 14: 61 \%)$, with species clustered towards R-selection (Fig. S3g). Perennial herbs had an SR/CSR median strategy $(25: 35: 41 \%)$ and occupied the entire triangle (Fig. S3h).

Some plant families were predominantly R-selected (e.g. Brassicaceae, Campanulaceae, Caryophyllaceae, Plantaginaceae; Fig. S4d,e,g,p), and others were dominated by Sselected species (Cyperaceae, Ericaceae, Juncaceae, Salicaceae; Fig. S4h,i,1,w) or were clustered around a relatively S-selected point (e.g. Rosaceae; 28:49:2\%, S/CSR; Fig. S4u). Poaceae exhibited a median strategy of S/CSR (15:53:33\%; Fig. S4q) and varied greatly between strategy extremes. A small number of families exhibited a relatively high degree of C-selection, such as Apiaceae (47:25:28\%, C/CSR; Fig. S4a).

\section{Discussion}

The globally calibrated CSR analysis method allowed strategies to be determined for a wide range of vascular plant species world-wide from habitats as diverse as tropical broadleaf rain forest, desert shrublands, mangroves and alpine pasture. The use of a small number of leaf traits has the advantage that large numbers of individuals or species comprising vegetation can be rapidly measured and compared. Indeed, studies of strategy variation within and between plant communities are currently applied inconsistently due to methodological constraints and measurement issues, but many of these can now be avoided due to the simplicity of the new method. For example, Schmidtlein, Feilhauer \& Bruelheide (2012) mapped CSR strategies across landscapes as a general indicator of changes in plant function across a mosaic of environments, but the traits used, and thus the overall analysis, were limited to herbaceous species and grassland vegetation. The current method will allow functional comparison of a much more inclusive set of vegetation types world-wide and will allow plant function to be considered in the broadest possible context. Despite the simplicity of the method, we have shown it to broadly represent plant functioning and to be consistent with expected patterns of plant function and along primary succession as predicted 


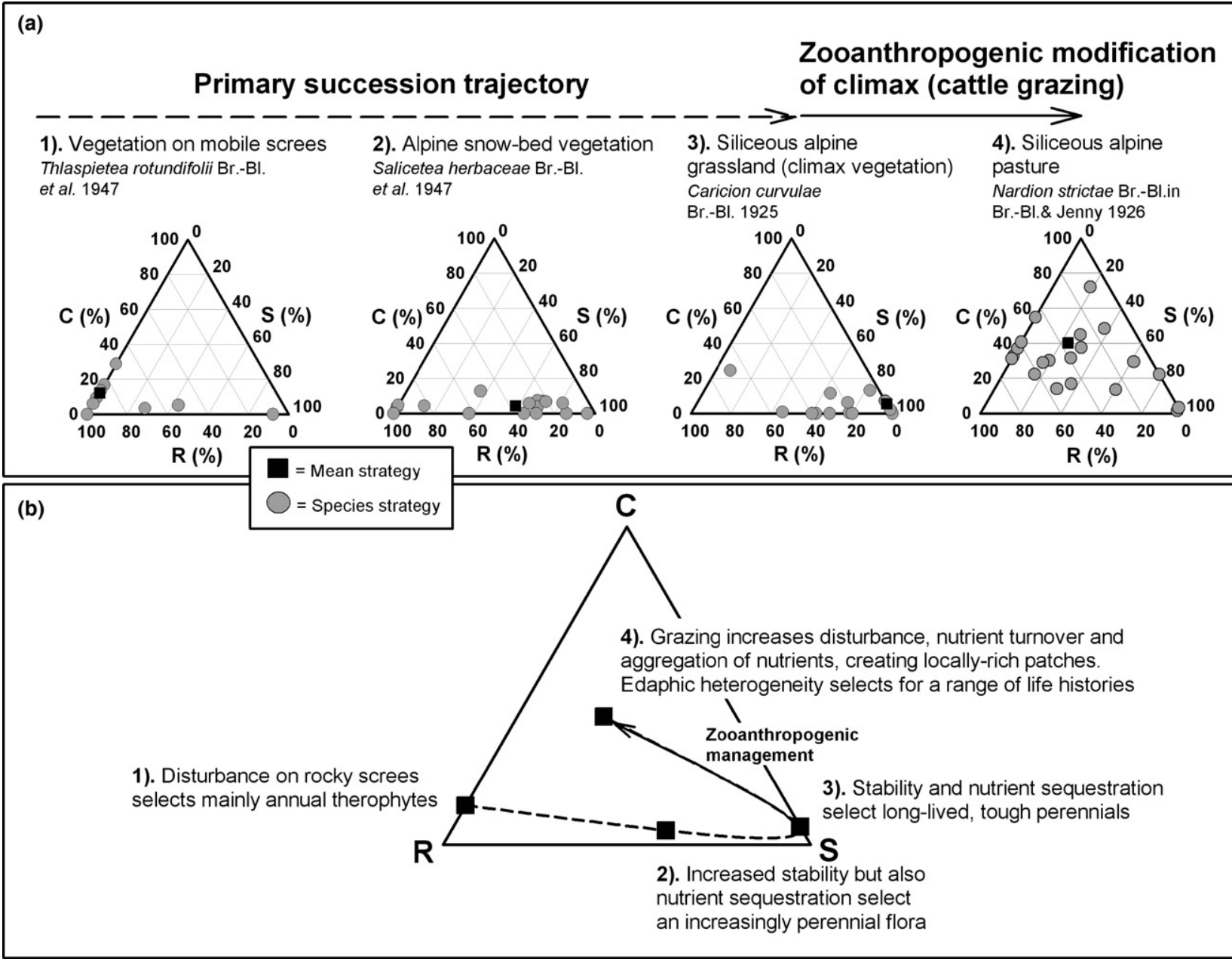

Fig. 4. An example of local application of the globally calibrated CSR analysis tool 'StrateFy' to species characteristic of phytosociological syntaxa undergoing primary succession following a trajectory from highly disturbed alpine scree slopes (Thlasietea rotundifolii Br.-Bl. et al. 1947) to siliceous grassland climax vegetation (Caricion curvulae Br.-Bl. 1925) further modified by cattle grazing to become alpine pasture (Nardion strictae Br.-Bl. in Br.Bl. \& Jenny 1926). Panel (a) shows separate plant communities recognized by classical phytosociology as phases in the succession sequence, and (b) a summary of the phytosociological 'evolution' of the vegetation represented as a trajectory in CSR space. Species data represent the mean of 10 replicate measurements for characteristic species of each syntaxon measured in the central Italian Alps.

by traditional phytosociological interpretation of vegetation.

Application of the CSR analysis to biomes world-wide revealed that certain biomes are characterized by relatively functionally restricted floras (i.e. clustered within particular zones of the CSR triangle), such as tropical and subtropical grasslands (median strategy CS/CSR; Fig. 5g). Others, sometimes despite the prevalence of extreme abiotic conditions, host comparatively uniform strategy distributions and wide variation within the CSR triangle. For example, deserts and xeric shrublands (Fig. 5m) include highly contrasting CSR strategies that reflected the presence of both xeromorphic stress tolerators (e.g. Larrea divaricata; C:S: $\mathrm{R}=1: 99: 0 \%, \mathrm{~S}$ ) and ruderal annual herbs (e.g. Claytonia perfoliata, 21:0:79\%, R/CR; Appendix S1), some of which occupy locally humid sites (e.g. R/CR-selected Mimulus guttatus). The idea that biological diversity in arid environments depends on highly contrasting perennial and annual life histories, microsite differences and niche differentiation is already well-established (e.g. Chesson et al. 2004). The value of CSR analysis is that it provides a quantitative method for comparing plant function between sites and geographic locations where equivalent ecological roles are performed by taxonomically distinct actors, for example L. divaricata, Cuphea ericoides (C:S:R =0:100:0\%; S) or Sebastiania ditassoides $(1: 99: 0 \% ; \mathrm{S})$.

As a further example of the wide applicability of the method beyond herbaceous vegetation, a range of CSR strategies was evident in tropical and subtropical forest biomes, but strategies were particularly clustered around the CS region as predicted (Fig. 5). Furthermore, a tradeoff was apparent between CS- and R-selection that was correlated with environmental gradients: CS-selection was associated with relatively stable situations (i.e. with less temperature seasonality) that were warmer and wetter, with greater annual precipitation and potential evapo- 
(a) Tropical and Subtropical Moist Broadleaf Forests (CS/CSR; $n=879$ )
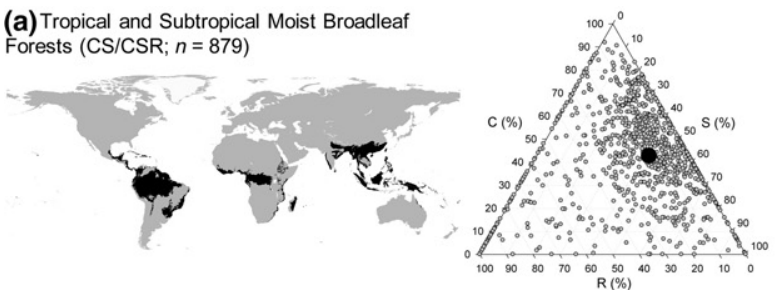

(c)Tropical and Subtropical Coniferous Forests (CS/CSR; $n=402$ )
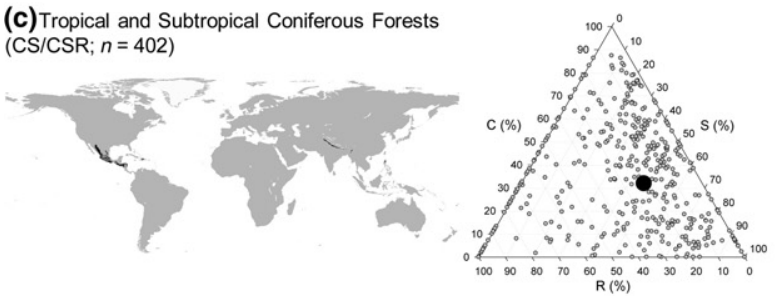

(e) Temperate Coniferous Forests (SR/CSR; $n=1901$ )
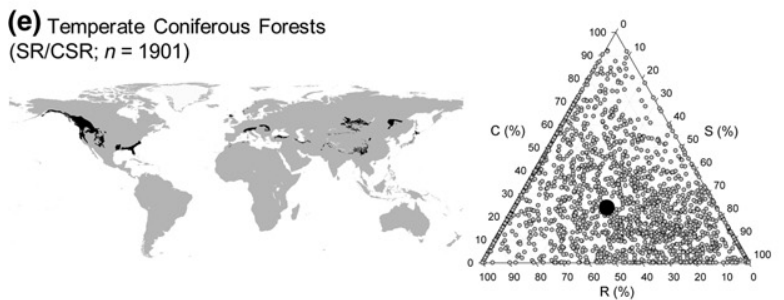

(g) Trop. and Subtrop. Grasslands, Savannas, and Shrublands ${ }_{100} \chi^{\circ}$

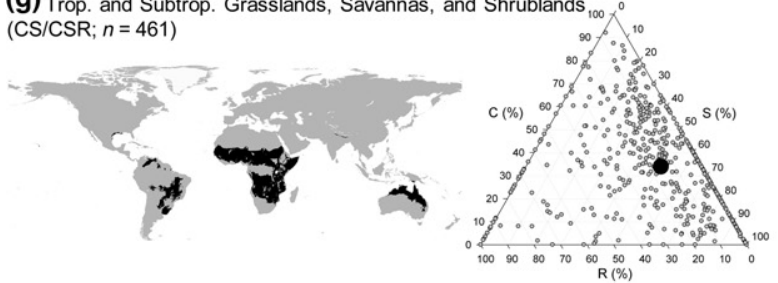

(i) Flooded Grasslands and Savannas (CSR; $n=110$ )
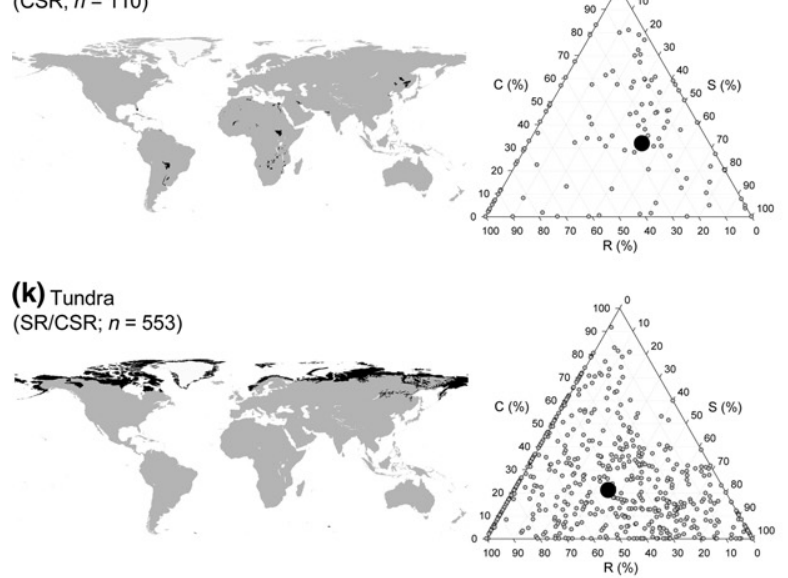

(m) Deserts and Xeric Shrublands $(\mathrm{CSR} ; n=621)$

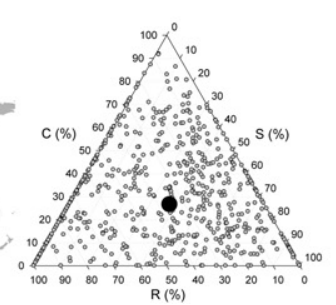

(b) Tropical and Subtropical Dry Broadleaf Forests (CS/CSR; $n=493$ )

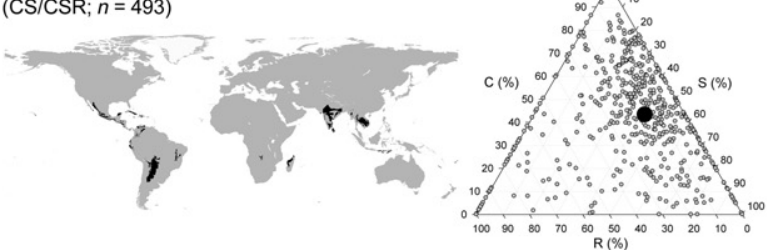

(d) Temperate Broadleaf and Mixed Forests (SR/CSR;
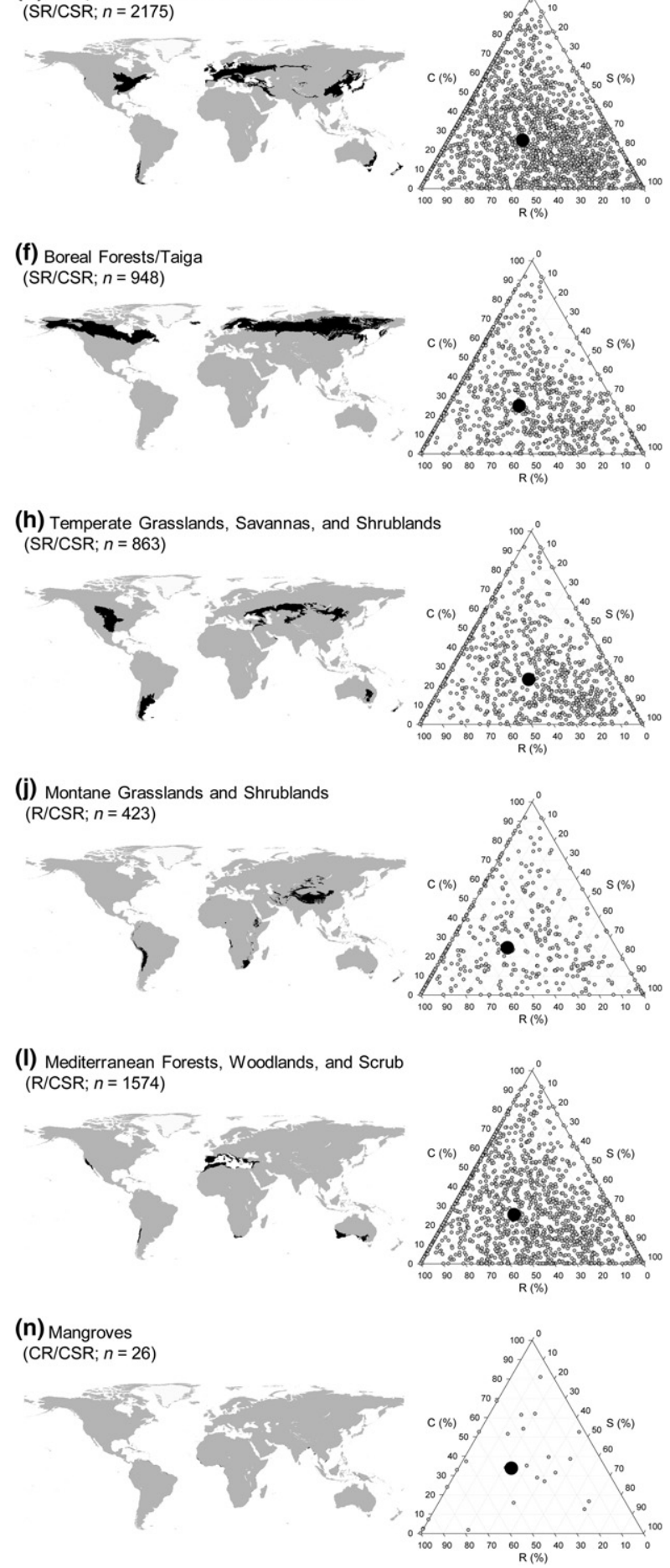

Fig. 5. Total (grey filled circles) and median (black filled circles) CSR strategies for 14 principal biomes world-wide (as defined by Olson et al. 2001). For each biome, median CSR category and sample size (number of species) are shown between parentheses. The distribution of each biome in the world map is denoted by black areas. 


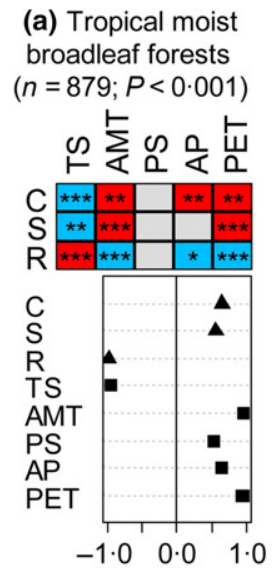

(b) Tropical dry
broadleaf forests
$(n=493 ; P<0.001)$

(c) Tropical

coniferous forests

.001) $\quad(n=402 ; P<0.001)$

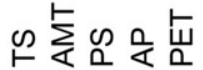

๗
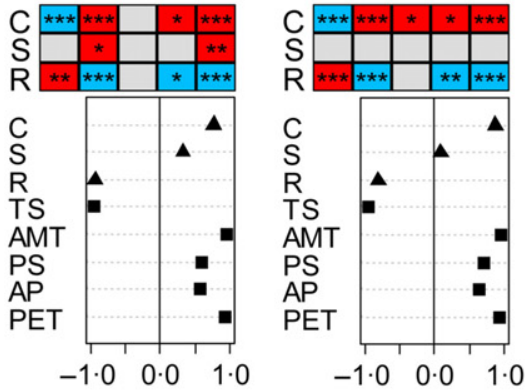

Correlation with RLQ axis 1

(e) Temperate coniferous forests

(f) Boreal forests/ taiga $(n=1901 ; P=0.723) \quad(n=948 ; P=0.002)$
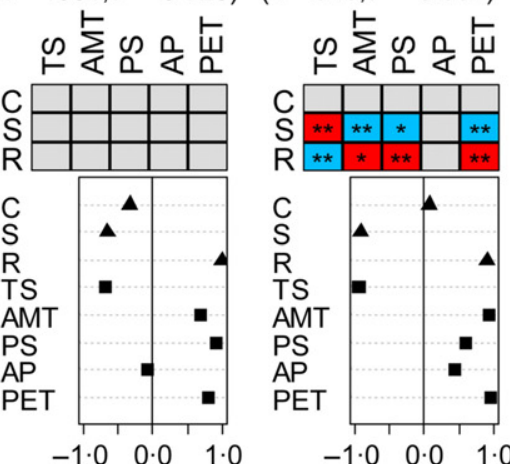

(g) Tropical

grasslands, savann. $(n=461 ; P<0.001)$

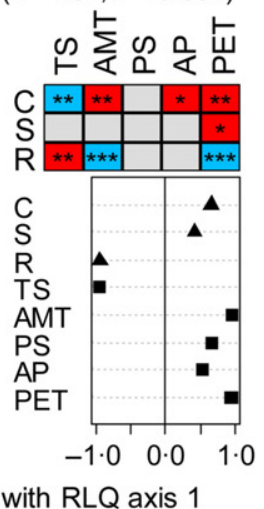

(i) Montane grasslands, shrubl. ( $n=423 ; P=0.662)$

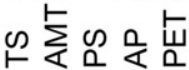
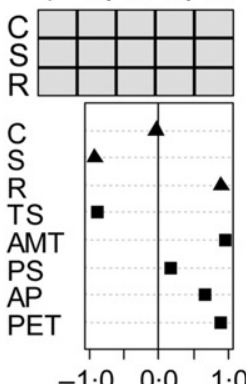

(j) Tundra

( $n=553 ; P=0.004)$

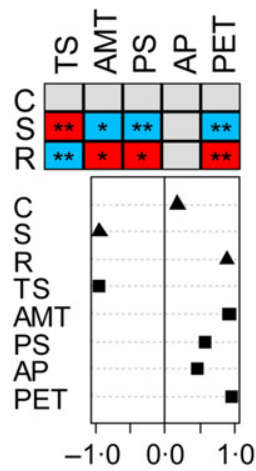

(k) Mediterranean forests, woodlands $(n=1574 ; P=0.233)$

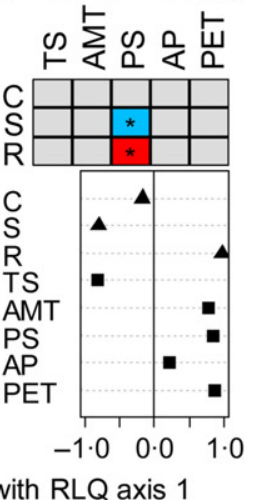

Correlation with $\mathrm{RLQ}$ axis 1 (d) Temperate

broadleaf forests

$(n=2175 ; P=0.367)$

の
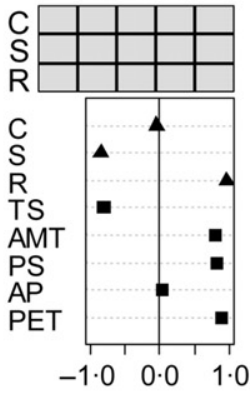

(h) Temperate

grasslands, savann

$(n=863 ; P=0.830)$

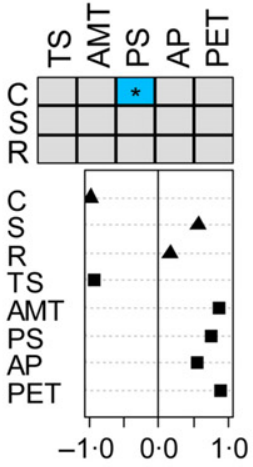

(I) Deserts and xeric shrublands $(n=621 ; P<0.001$,

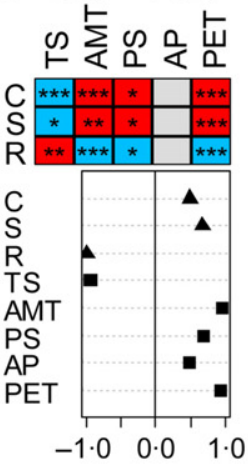

Fig. 6. Global-scale fourth-corner analysis (coloured grids) and RLQ analysis (white dot charts) of the relationship between CSR strategies and environmental variables within biomes: (a) tropical moist broadleaf forests; (b) tropical dry broadleaf forests; (c) tropical coniferous forests; (d) temperate broadleaf and mixed forests; (e) temperate coniferous forests; (f) boreal forests/ taiga; (g) tropical grasslands, savannas and shrublands; (h) temperate grasslands, savannas and shrublands; (i) montane grasslands and shrublands; (j) tundra; (k) Mediterranean forests and scrub; (l) deserts/xeric shrublands. TS $=$ temperature seasonality; AMT = annual mean temperature; $\quad \mathrm{PS}=$ precipitation seasonality; $\mathrm{AP}=$ annual precipitation; $\mathrm{PET}=$ global potential evapo-transpiration). Fourth-corner statistic: red $=$ positive, blue $=$ negative, $\quad$ grey $=$ not significant, $* P<0.05$; $* * P<0.01 ; * * * P<0.001 \quad(n=$ number of species, $P=$ significance for the overall association between $\mathrm{C}$-, S- and R-selection and environmental variables). transpiration. Pioneer species in tropical forests were found to be relatively $\mathrm{C}$-selected, such as Neotropical Cecropia longipes $(\mathrm{C})$, Ficus insipida $(\mathrm{C} / \mathrm{CS})$ and Urera baccifera (C/CR; Appendix Table S1). Indeed, although disturbances and ruderal species are present in tropical forests, disturbance is not a prevalent factor in the same way that regular grazing or cutting determines the general character of pastures or meadows. Instabilities such as gap formation in tropical forests are local events that do not shape the forest in its entirety. Gap formation in particular is characterized by a pulse of light availability, and the ensuing competition apparently favours C-selection with succession proceeding relatively uninterrupted towards a closed tree canopy. Canopy tree species in tropical moist forest were shown to exhibit a stress tolerance component (e.g. Brosimum alicastrum, CS; Platypodium elegans, CS/ CSR; Prioria copaifera, CS). This perhaps reflects local sequestration of resources in long-lived tissues in later successional stages (Grime 2001), or increasing adaptation to drought tolerance (Engelbrecht et al. 2007; Baltzer et al. 
2008). R-selected tropical rain forest species were evident and potentially occupy specific microsites at fine scales. The high diversity of tropical forests may also partly be related to specific, single traits operating during the life cycle, such as flowering and fruiting characters and symbioses (Grime \& Pierce 2012). The many and varied mechanisms proposed to explain higher diversity at low latitudes (discussed by Gaston 2000) probably apply as much to functional diversity as they do to taxonomic diversity, with geographic area and environmental stability (both seasonal and historical) being amongst the most evident factors affecting the creation of species richness.

Globally, the variation in strategies within biomes is likely to be influenced by the presence of contrasting growth forms. Forbs exhibited extremely broad strategy diversity and a generalist median strategy of R/CSR, while trees ranged from $\mathrm{C}$ to $\mathrm{S}$, with a $\mathrm{CS}$ median strategy similar to the CS/CSR median strategies evident in tropical forests (Fig. S3). The presence or absence of particular strategies at a given location is also likely to be affected by historical and phylogenetic constraints, with restriction of CSR strategies evident in some families but not others (Fig. S4).

The 'strategy of a species' as presented here is an average calculated from individuals of each species sampled at a particular location. Ecotypic variation throughout the home range of a species and phenotypic plasticity could potentially broaden the range of strategy variation for a given species and is a complicating factor when CSR strategies measured at one site are assumed to be relevant to other situations. Thus, consideration of the CSR strategy of a species across a biome world-wide, as in the present study, should be interpreted with caution and should be seen as a summary or abstract for the species in lieu of trait data for all populations throughout the geographic range: this is the best that can be managed with current global data sets. Future detailed study of the functional differences between biomes should ideally involve replicated surveys within a range of habitat types and would be a massive undertaking involving a great deal of international cooperation and funds. Indeed, the biome-level analysis presented here was limited by the lack of available data regarding the relative abundance of species within biomes at the global scale and could not differentiate between prevalent and rare strategies. Thus, median CSR strategies for each biome were not weighted and rare species will have had a disproportionally strong influence on the median strategy. Indeed, median strategies for biomes were generally located towards the centre of the triangle (Fig. 5).

Nonetheless, just as species richness and taxonomic identities are fundamental aspects of plant diversity, 'strategy richness' and the character of the strategies present are important aspects of ecological diversity that can now easily be quantified and compared. In local-scale studies in which relative abundance has been quantified, differing degrees of dominance between CSR strategies are evident. For example, microsite differences and niche partitioning between contrasting CSR strategies have been invoked as a mechanism of coexistence and local biodiversity creation on Brazilian coastal Atlantic forest inselbergs (de Paula et al. 2015). Similarly, xeric sand calcareous grasslands in Europe include a mixture of relatively abundant stress-tolerator graminoids and larger numbers of infrequent ruderal or competitive-ruderal herbs, and CSR strategies are thus markedly different between dominant and subordinate plants at the centimetre scale (Pierce et al. 2014b). Future application of CSR analysis in further bio-geographical and ecological contexts world-wide will allow general conclusions with regard to how the equilibrium between dominant and subordinate species may change in response to environmental perturbation and with regard to the precise relationships between microsite factors and particular plant species.

In conclusion, the CSR analysis tool derived from 116979 records of leaf size and economics traits measured from 3068 species growing in nature world-wide has allowed a preliminary CSR analysis of major biome classes globally. The $\mathrm{C}, \mathrm{S}$ and $\mathrm{R}$ values were in agreement with phytosociological observations of vegetation responses to an environmental gradient along a primary succession. Thus, the global system is consistent with earlier locally calibrated methods and studies of plant strategies and can provide a functional explanation consistent with descriptive phytosociological methods of interpreting vegetation. A unified framework now exists for ecological strategy classification, using readily determined leaf traits of plants as diverse as temperate ferns, lianas and tropical trees. The global strategy-environment relationships that the method can resolve will form a baseline for predicting which kinds of species can be expected to assemble where in response to environmental perturbation resulting from factors such as climatic or land-use changes.

\section{Acknowledgements}

The study has been supported by the TRY initiative on plant traits (www.try-db.org). The TRY initiative and data base is hosted, developed and maintained by J.K. and G. Bönisch (Max-Planck-Institute for Biogeochemistry, Jena, Germany). TRY is/has been supported by DIVERSITAS, IGBP, the Global Land Project, the UK Natural Environment Research Council (NERC) through its program QUEST (Quantifying and Understanding the Earth System), the French Foundation for Biodiversity Research (FRB), and GIS 'Climat, Environnement et Société' France. We thank Daniel Laughlin, Frédérique Louault, Belinda Medlyn, Julie Messier, Juli Pausas and Ian Wright for contributing data. The authors declare no conflict of interest.

\section{Data accessibility}

All data are archived and are available from the TRY plant trait data base: www.try-db.org.

\section{References}

Baltzer, J.L., Davies, S.J., Bunyavejchewin, S. \& Noor, N.S.M. (2008) The role of desiccation tolerance in determining tree species distributions along the Malay-Thai Peninsula. Functional Ecology, 22, 221-231. 
van Bodegom, P.M., Douma, J.C., Witte, J.P.M., Ordoñez, J.C., Bartholomeus, R.P. \& Aerts, R. (2012) Going beyond the limitations of plan functional types when predicting global ecosystem-atmosphere fluxes: exploring the merits of traits-based approaches. Global Ecology and Biogeography, 21, 625-636.

Braun-Blanquet, J. (1925) Zur wertung der gesellschaftstreue in der pflanzensoziologie. Vierteljahrsschrift der Naturforschenden Gesellschaft in Zürich, 70, 122-149.

Bunce, R.G.H., Smart, S.M., devan Poll, H.M., Watkins, J.W. \& Scott, W.A. (1999) ECOFACT 2 - Measuring Change in British vegetation. Institute of Terrestrial Ecology Monks Wood, Huntingdon, UK.

Caccianiga, M., Luzzaro, A., Pierce, S., Ceriani, R.M. \& Cerabolini, B. (2006) The functional basis of a primary succession resolved by CSR classification. Oikos, 112, 10-20.

Cerabolini, B.E.L., Brusa, G., Ceriani, R.M., De Andreis, R., Luzzaro, A \& Pierce, S. (2010) Can CSR classification be generally applied outside Britain? Plant Ecology, 210, 253-261.

Cerabolini, B.E.L., Pierce, S., Verginella, A., Brusa, G., Ceriana, R.M. \& Armiraglio, S. (2016) Why are many anthropogenic agroecosystems particularly species rich? Plant Biosystems, 150, 550-557.

Chesson, P., Gebauer, R.L.E., Schwinning, S., Huntly, N., Wiegand, K., Ernest, S.K. et al. (2004) Resource pulses, species interactions, and diversity maintenance in arid and semi-arid environments. Oecologia, 141, 236-253.

Cornelissen, J.H.C. \& Cornwell, W.K. (2014) The Tree of Life in ecosystems: evolution of plant effects on carbon and nutrient cycling. Journal of Ecology, 102, 269-274.

Cornwell, W.K., Cornelissen, J.H.C., Amatangelo, K., Dorrepaal, E., Eviner, V.T., Godoy, O. et al. (2008) Plant species traits are the predominant control on litter decomposition rates within biomes worldwide. Ecology Letters, 11, 1065-1071.

Cornwell, W.K., Westoby, M., Falster, D.S., FitzJohn, R.G., O'Meara, B.C., Pennell, M.W. et al. (2014) Functional distinctiveness of major plant lineages. Journal of Ecology, 102, 345-356.

Díaz, S., Kattge, J., Cornelissen, J.H.C., Wright, I.J., Lavorel, S., Dray, S. et al. (2016) The global spectrum of plant form and function. Nature, 529, $167-171$

Dray, S., Chessel, D. \& Thioulouse, J. (2003) Co-inertia analysis and the linking of ecological data tables. Ecology, 84, 3078-3089.

Dray, S. \& Dufour, A.B. (2007) The ade4 package: implementing the duality diagram for ecologists. Journal of Statistical Software, 22, 1-20.

Dray, S., Choler, P., Dolédec, S., Peres-Neto, P.R., Thuiller, W., Pavoine, S. et al. (2014) Combining the fourth-corner and the RLQ methods for assessing trait responses to environmental variation. Ecology, 95, 14-21.

Engelbrecht, B.M.J., Comita, L.S., Condit, R., Kursar, T.A., Tyree, M.T., Turner, B.L. et al. (2007) Drought sensitivity shapes species distribution patterns in tropical forests. Nature, $\mathbf{4 4 7}, 80-82$

Flores, O., Garnier, E., Wright, I.J., Reich, P.B., Pierce, S., Díaz, S. et al. (2014) An evolutionary perspective on leaf economics in vascular plants: phylogenetic patterns in LMA. Ecology and Evolution, 4, 2799-2811.

Gaston, K.J. (2000) Global patterns in biodiversity. Nature, 405, 220-227.

Gennai, M., Foggi, B., Viciani, D., Carbognani, M. \& Tomaselli, M. (2014) The Nardus-rich communities in the Northern Apennines (N-Italy): a phytosociological, ecological and phytogeographical study. Phytocoenologia, 44, 55-80.

Grime, J.P. (1974) Vegetation classification by reference to strategies. Nature, 250, 26-31

Grime, J.P. (1977) Evidence for the existence of three primary strategies in plants and its relevance to ecological and evolutionary theory. American Naturalist, 111, 1169-1194.

Grime, J.P. (2001) Plant Strategies, Vegetation Processes and Ecosystem Properties, Second edn. Wiley, Chichester, UK.

Grime, J.P., Hodgson, J.G. \& Hunt, R. (1988) Comparative Plant Ecology: A Functional Approach to Common British Species. Unwin Hyman, London, UK

Grime, J.P. \& Pierce, S. (2012) The Evolutionary Strategies that Shape Ecosystems. Wiley-Blackwell, Chichester, UK.

Grime, J.P., Thompson, K., Hunt, R., Hodgson, J.G., Cornelissen, J.H.C., Rorison, I.H. et al. (1997) Integrated screening validates primary axes of specialisation in plants. Oikos, 79, 259-281.

Hijmans, R.J., Cameron, S.E., Parra, J.L., Jones, P.G. \& Jarvis, A. (2005) Very high resolution interpolated climate surfaces for global land areas. International Journal of Climatology, 25, 1965-1978.

Hodgson, J.G., Wilson, P.J., Hunt, R., Grime, J.P. \& Thompson, K. (1999) Allocating CSR plant functional types: a soft approach to a hard problem. Oikos, 85, 282-294.
Hunt, R., Hodgson, J.G., Thompson, K., Bungener, P., Dunnett, N.P. \& Askew, A.P. (2004) A new practical tool for deriving a functional signature for herbaceous vegetation. Applied Vegetation Science, 7, 163-170.

Kattge, J., Díaz, S., Lavorel, S., Prentice, I.C., Leadley, P., Bönisch, G. et al. (2011) TRY - a global database of plant traits. Global Change Biology, 17, 2905-2935.

Kleyer, M., Bekker, R.M., Knevel, I.C., Bakker, J.P., Thompson, K., Sonnenschein, M. et al. (2008) The LEDA Traitbase: a database of life-history traits of the Northwest European flora. Journal of Ecology, 96, 1266-1274.

Kreft, H. \& Jetz, W. (2007) Global patterns and determinants of vascular plant diversity. Proceedings of the National Academy of Sciences of the United States of America, 104, 5925-5930.

Lepš, J., Osbornová-Kosinová, J. \& Rejmánek, M. (1982) Community stability, complexity and species life history strategies. Vegetation, 50, 5363.

Negreiros, D., Le Stradic, S., Fernandes, G.W. \& Rennó, H.C. (2014) CSR analysis of plant functional types in highly diverse tropical grasslands of harsh environments. Plant Ecology, 215, 379-388.

Olson, D.M., Dinerstein, E., Wikramanayake, E.D., Burgess, N.D., Powell, G.V.N., Underwood, E.C. et al. (2001) Terrestrial ecoregions of the world: a new map of life on Earth. BioScience, 51, 933-938.

de Paula, L.F.A., Negreiros, D., Azevedo, L.O., Fernandes, R.L., Stehmann, J.R. \& Silveira, F.A.O. (2015) Functional ecology as a missing link for conservation of a resource-limited flora in the Atlantic Forest. Biodiversity and Conservation, 24, 2239-2253.

Pierce, S., Luzzaro, A., Caccianiga, M., Ceriani, R.M. \& Cerabolini, B. (2007a) Disturbance is the principal $\alpha$-scale filter determining niche differentiation, coexistence and biodiversity in an alpine community. Journal of Ecology, 95, 698-706.

Pierce, S., Ceriani, R.M., De Andreis, R., Luzzaro, A. \& Cerabolini, B. (2007b) The leaf economics spectrum of Poaceae reflects variation in survival strategies. Plant Biosystems, 141, 337-343.

Pierce, S., Brusa, G., Sartori, M. \& Cerabolini, B.E.L. (2012) Combined use of leaf size and economics traits allows direct comparison of hydrophyte and terrestrial herbaceous adaptive strategies. Annals of Botany, 109, 1047-1053.

Pierce, S., Brusa, G., Vagge, I. \& Cerabolini, B.E.L. (2013) Allocating CSR plant functional types: the use of leaf economics and size traits to classify woody and herbaceous vascular plants. Functional Ecology, 27, 1002-1010.

Pierce, S., Bottinelli, A., Bassani, I., Ceriani, R.M. \& Cerabolini, B.E.L. (2014a) How well do seed production traits correlate with leaf traits, whole plant traits and plant ecological strategies? Plant Ecology, 215, 1351-1359.

Pierce, S., Vagge, I., Brusa, G. \& Cerabolini, B.E.L. (2014b) The intimacy between sexual traits and Grime's CSR strategies for orchids coexisting in semi-natural calcareous grassland at the Olive Lawn. Plant Ecology, 215, 495-505.

Podani, J. (2007) Analisi ed Esplorazione Multivariata dei Dati in Ecologia e Biologia. Liguori Editori, Napoli, Italy (in the Italian language).

R Development Core Team (2013) R: A Language and Environment for Statistical Computing. R Foundation for Statistical Computing, Vienna. http://www.r-project.org [accessed 2 November 2013]

Reich, P.B. (2014) The world-wide 'fast-slow' plant economics spectrum: a traits manifesto. Journal of Ecology, 102, 275-301.

Santiago, L.S. \& Wright, S.J. (2007) Leaf functional traits of tropical forest plants in relation to growth form. Functional Ecology, 21, 19-27.

Schmidtlein, S., Feilhauer, H. \& Bruelheide, H. (2012) Mapping plant strategy types using remote sensing. Journal of Vegetation Science, 23, 395405

Soudzilovskaia, N.A., Elumeeva, T.G., Onipchenko, V.G., Shidakov, I.I., Salpagarova, F.S., Khubiev, A.B. et al. (2013) Functional traits predict relationship between plant abundance dynamic and long-term climate warming. Proceedings of the National Academy of Sciences of the United States of America, 110, 18180-18184.

Tomaselli, M. (1997) Ecogeografical gradients in Salix herbacea vegetation of the Alps. Actes du Colloque Ecologie et Biogeographie Alpines. La Thuile 2-6 Septembre 1990. Suppl. Rev. Vald. d'Hist. Nat., 48, 1994. pp. $335-346$

Tomaselli, M. \& Rossi, G. (1994) Phytosociology and ecology of Caricion curvulae vegetation in the northern Apennines (N Italy). Fitosociologia, 26, 51-62.

Trabucco, A. \& Zomer, R.J. (2009) Global Aridity Index (Global-Aridity) and Global Potential EvapoTranspiration (Global-PET) geospatial database. CGIAR Consortium for Spatial Information. http://www.cgiarcsi.org/ [accessed 14 October 2014]. 
Verheijen, L.M., Aerts, R., Bönisch, G., Kattge, J. \& Van Bodegom, P.M. (2016) Variation in trait trade-offs allows differentiation among predefined plant functional types: implications for predictive ecology. New Phytologist, 209, 563-575.

Warton, D.I. \& Hui, F.K.C. (2011) The arcsine is asinine: the analysis of proportions in ecology. Ecology, 92, 3-10.

Wright, I.J., Reich, P.B., Westoby, M., Ackerly, D.D., Baruch, Z., Bongers, F. et al. (2004) The worldwide leaf economics spectrum. Nature, $\mathbf{4 2 8}$, $821-827$.

Received 14 September 2015; accepted 23 July 2016

Handling Editor: Jennifer Baltzer

\section{Supporting Information}

Additional Supporting Information may be found online in the supporting information tab for this article:

Fig. S1. Regressions between transformed values of a) leaf area (LA), b) leaf dry matter content (LDMC), and c) specific leaf area
(SLA) and PCA axis scores for 3068 tracheophyte species from across the world.

Fig. S2. Regressions between the degree of C-, S- and R-selection (panels a, b, and c, respectively) as determined by the globally-calibrated method ( $x$-axis) and the CSR analysis method of Pierce et al. (2013) calibrated using the Flora of Italy ( $y$-axis).

Fig. S3. CSR strategies of growth habit categories for 3068 species from across the world, calculated using the globally-calibrated CSR analysis tool 'StrateFy'.

Fig. S4. CSR strategies for major flowering plant families (i.e. those most highly represented in the database; minimum 30 species), calculated using the globally-calibrated CSR analysis tool 'StrateFy'.

Table S1. Species list including authorities, life forms, biome information and CSR strategies.

Table S2. 'StrateFy', the global vascular plant CSR calculator tool in Microsoft Excel format. 